In Europe, Dr Muijen emphasises the importance of the movement that aims to encourage the establishment of community-based mental health services. Even in Europe, there is a serious treatment gap - estimated to be up to $50 \%$ (i.e. only half of those requiring mental health support are getting it). The UK is an example of a country that has relatively few in-patient services, and in fact is on a par with Albania and Turkey, but, unlike those countries, the UK has invested heavily in community mental health. There are exemplars of good practice in Eastern as well as in Western Europe, but they are few in number. The establishment of good quality community services is challenging at many different levels and cannot be achieved by centralised planning alone. Dr Muijen pleads for better training in managing service development for psychiatrists in general.

In the Eastern Mediterranean, Drs Saeed and Gater discuss how their Regional Office has recently devised a plan to promote mental health provision in the 23 countries incorporated into this authority. As in so many other parts of the world, despite there being a tremendous burden on mental health services arising from regional conflicts, economic challenges and immigration, the investment by governments in mental healthcare amounts to no more than $5 \%$ of that recommended globally. These authors propose a six-point strategic plan, based on the development of community psychiatry provision, which could be implemented on a limited budget within the next 5 years. The strategy emphasises decentralised community services in the context of forward-thinking national policies, with a research infrastructure that will allow full evaluation of implementation and progress.

Finally, in South-East Asia Dr Anwar and colleagues discuss the changes in their region in the context of gross underfunding and a paucity of psychiatrists (just a sixth of the median number per head of population in global terms). In order to tackle this shortfall, which is not going to be correctable in the foreseeable future, the SouthEast Asia Regional Office has decided to train community-based health workers to recognise serious mental and neurological disorders; treatment will then be provided by a primary care physician. Their emphasis in the first phase of this plan will be upon epilepsy, psychosis and depression. A number of pilot projects have already been established.

\section{THEMATIC} PAPER

\title{
Scaling up in Europe: learning from diversity
}

\author{
Matt Muijen
}

Programme Manager Mental Health, WHO Regional Office for Europe, email mfm@euro.who.int
Over the past decade, attention has increasingly focused on the need to increase the capacity of mental health services. The World Health Report 2001 - Mental Health: New Understanding, New Hope (World Health Organization, 2001) set the agenda, advocating the development of community-based mental health services. The case for scaling up, inspired by the World Health Organization's vision of 'no health without mental health', was powerfully argued first in the Lancet series in 2007 (Prince et al, 2007) and again in the Lancet in 2011 (Eaton et al, 2011). The forthcoming Global Mental Health Action Plan, requested in a resolution by member states of the World Health Organization at the $\mathbf{2 0 1 2}$ World Health Assembly, is a great opportunity to formulate objectives and targets for countries, and to analyse experiences from around the world. The forthcoming European Action Plan builds on this, customising actions for European countries.

The case for scaling up has been persuasively and consistently made by these and many other papers. On the one hand, the need for care is great, as demonstrated by annual prevalence rates estimated to be high as $38 \%$ (Wittchen et al, 2011) and a contribution of mental disorders to the global burden of disease of $13 \%$. On the other, a treatment gap has been reported of about $80 \%$.

Service capacity cannot cope with need. The world's median number of mental health beds is 7 per 100000 and of psychiatrists it is 1.3 per 100000 (World Health Organization, 2012). However, reliance on global medians risks overlooking diversity. In Europe, the median bed number in mental hospitals is 39 per 100000 , and the median number of psychiatrists is 8.6, rather contrasting with the medians of 1.7 beds and 0.05 psychiatrists reported in Africa. In Europe, median average expenditure on psychotropic medication per 100000 population is US\$2.6 million, in Africa US $\$ 2300$, more than 1000-fold less. Obviously, such differences are a reflection of budgets. In Europe, $5 \%$ of the relatively high health budgets are allocated to mental health, in Africa $0.6 \%$ of the much lower health budgets. However, even in Europe the treatment gap is still between $35 \%$ and $50 \%$ (Kohn et al, 2004).

The relatively high resource level in Europe has enabled the development of comprehensive mental health services in many countries, but 
the variation within Europe is also striking. The number of beds per 100000 ranges from 150 to 8 , and psychiatrists from 30 to 1 (World Health Organization Regional Office for Europe, 2008). Surprisingly, the diversity is not associated with resources alone. It is also related to differences in the models of care. For example, the lowest bed rates can be found in Albania, England, Greece, Turkey and Italy. England, though, has the highest mental health spending level as a proportion of total health budget. The explanation is that the proportion of the mental health budget allocated to psychiatric beds is only $26 \%$, allowing heavy investments in a range of community-based services. Albania and Turkey, in contrast, with low mental health budgets, have low numbers of psychiatrists, beds and community-based services.

These differences in resources and models pose very different opportunities and challenges for policy and service development. For example, in Italy and England, the challenge was how to transfer the high investment in institutions to community services, with the aim of offering more humane and effective services. Each country approached this in a different fashion. Italy passed national legislation forcing the closure of hospitals. The development of community services was the responsibility of provincial health authorities. In England, a hospital closure programme was introduced. A national mental health service model was adopted, specifying in detail the number and type of teams and staff that should be available in every part of the country. Central funding was provided and progress was carefully monitored. As a consequence, Italian mental healthcare is very diverse, varying from excellent individual needs-based community care to very limited supply, depending on the wealth and the commitment of the local community. Similar challenges of decentralisation can be found in federal states such as Spain, Germany and Scandinavian countries. In England, services used to be remarkably homogeneous and comprehensive, covering crisis, early intervention, assertive outreach and psycho-rehabilitation, supported by beds in general hospitals. The challenges of monitoring quality and securing supply remain, particularly when budget cuts require decisions about priorities.

A very different challenge is to develop community-based mental health services starting from a low resource level. Most European countries outside the 'old' European Union have mental health services that are dominated by mental hospitals. Treatment is centred on the prescription of medication, since very few psychologists, occupational therapists and social workers are employed in mental health services. Typically about $80 \%$ of the budget is committed to such institutions. Some countries are taking on the challenge. In Turkey, the Ministry of Health launched a national action plan, supported by both the European Union and the World Health Organization, and community services have been introduced nationally. The large mental hospitals are due to close and beds will be provided in district general hospitals. The workforce is being expanded and trained.

Not every country is moving forward on such a scale, but in every country some examples of exciting and innovative practice can be found. Romania is a country that is struggling to implement its national model of community services owing to austerity measures. In one area, Câmpulung Moldovenesc, a small mental hospital with 40 beds and 20 places in the day hospital separated from the large general hospital and developed a wide range of services. It now combines acute in-patient care with a community mental health centre. A mobile team offers social interventions in small towns and rural communities within the psychiatric sector. Social interventions are provided in close partnership with 12 local authorities and voluntary agencies. The mobile team also provides home treatment for people with mental health problems who have been placed in protected houses, on the basis of a personalised plan. The hospital offers church services in the hospital church that are attended both by patients and by the local population, and it organises community classes in cooking, painting, ceramics and sewing as well as birthday parties and cultural activities. This model was inspired by the vision of a local leader, Dr Alexandru Paziuc, who was able to galvanise mental health staff and community leaders.

Some countries benefit from external investment and expertise, although the effects are not always predictable. Such centres can succeed as pilot services, inspiring others. Alternatively, they can become isolated. In one Central European country, a foreign donor funded a local community centre. It was based on the ground floor of the poly-clinic, beautifully renovated, with many large rooms and well equipped. The centre employed a full-time psychiatrist, psychologist, occupational therapist, nurses and support staff. About 25 clients attended daily, involved in occupational activities, most from within walking distance of the centre since transport was not provided. In stark contrast, the standard clinic, referred to as obsolete by the community centre, comprised two crammed rooms on a first floor, and was staffed by three psychiatrists, each supported by a nurse. They were responsible for several thousand patients, from all over the district, and were in regular contact with family doctors. As a consequence of pressure and budget restrictions, they could offer only limited interventions, although they had many ideas on how to develop in response to local needs. The two services ran in parallel, with no cross-referrals.

The challenges and opportunities, even in the European region, with its relatively well resourced countries, are diverse, but there are some common conclusions. One is that tension exists between central planning and local implementation. National action plans, drafted in almost every country, are necessary, prescribing the model of care and identifying the necessary resources. A sufficient supply of specialist mental health staff working in close partnership with primary care 
teams is crucial to success. In most countries, this requires an expansion of training places and an increase in the capacity of universities.

A second, connected conclusion is that the establishment of modern mental health services is not simply the rational dissemination of evidencebased models of care. Whereas the implementation of a national hospital plan can indeed be achieved by replicating the same building and workforce plans around the country, community services require major local adaptations and strong local commitments. Local leaders need to inspire change and instigate partnerships. Mostly, it is assumed that local psychiatrists can deliver this, and occasionally they can.

It needs to be recognised that the transformation of mental health services demands leadership and competence in change management. This should be considered a professional skill, as taught at management schools. However, it is all but absent from psychiatric curricula, and training opportunities are rare. It now needs to be accepted that such change management skills belong under the core competencies of psychiatrists.

Mental health reforms are proceeding around the globe, and the World Health Organization's
Global Action Plan and the European Action Plan identify some of the steps required. But essential are local commitment and the availability and skills of local change management, sustained over time. Respectful partnership between international guidance, national plans and local expertise is the recipe for progress.

\section{References}

Eaton, J., McCay, L., Semrau, M., et al (2011) Scale up of services for mental health in low-income and middle-income countries. Global mental health 4. Lancet, 378, 1592-1603.

Kohn, R., Saxena, S., Levav, I., et al (2004) The treatment gap in mental health care. Bulletin of the World Health Organization, 82 , 858-866.

Prince, M., Patel, V., Saxena, S., et al (2007) No health without mental health. Global mental health 1. Lancet 370, 859-877.

Wittchen, H. U., Jacobi, F., Rehm, J., et al (2011) The size and burden of mental disorders and other disorders of the brain in Europe 2010. European Neuropsychopharmacology, 21, 655-679.

World Health Organization (2001) The World Health Report 2001 Mental Health: New Understanding, New Hope. WHO.

World Health Organization (2012) Mental Health Atlas 2011 WHO.

World Health Organization Regional Office for Europe (2008) Policies and Practices for Mental Health in Europe. WHO Regional Office for Europe.
THEMATIC PAPER

\title{
Strategic vision for mental health and substance misuse in the Eastern Mediterranean Region
}

\author{
Khalid Saeed ${ }^{1}$ and Richard Gater ${ }^{2}$
}

${ }^{1}$ Regional Advisor, Mental Health and Substance Abuse, Division of Health Promotion and Protection, World Health Organization Regional Office for the Eastern Regional Office for the Easter
Mediterranean, Cairo, Egypt, Mediterranean, Cairo, Egypt,
email Saeedk@emro.who.int

${ }^{2}$ Senior Lecturer in Psychiatry, University of Manchester and Honorary Consultant Psychiatrist, Lancashire Care NHS Foundation Trust, UK
The Eastern Mediterranean Region of the World Health Organization has recently developed a comprehensive strategy and action plan to promote mental health and provide for the integrated prevention, treatment and rehabilitation of mental, neurological and substance use disorders. By strengthening national mental health policies, plans and legislation, scaling up integrated services, capacity-building, promoting human rights and prioritising vulnerable groups, the strategy aims to improve mental health and to help countries achieve their national development objectives.

The Eastern Mediterranean is one of the six regions of the World Health Organization (WHO). Its 23 member countries, from Pakistan in the east to Morocco in the west, have a combined population of almost 600 million (10\% of the global population). The region is undergoing rapid demographic, sociocultural and political transition and several countries are experiencing humanitarian emergencies. This has resulted in migration, internal displacement, unplanned urbanisation and changes in family role, which pose a threat to health and impair the capacity of health systems to deliver services. Wealth from the discovery of oil has facilitated significant improvements in education, literacy and life expectancy in some countries, while others are among the poorest in the world.

Mental, neurological and substance (MNS) disorders account for the loss of $11 \%$ of disabilityadjusted life-years and for $27 \%$ of the years lived with disability in the region (WHO, 2004). Despite the burden and economic impact of MNS disorders, the median annual investment in mental healthcare of US $\$ 0.15$ per person in the region's countries (WHO Regional Office for the Eastern Mediterranean, 2010) is well below the US\$3-9 needed for a recommended package of costeffective mental health interventions in low- and middle-income countries (Hyman et al, 2006).

The past decade has witnessed a number of global initiatives to improve mental health, 